\title{
Large-Scale Features of the Novorossiysk Bora
}

\author{
V. V. Efimov*, O. I. Komarovskaya
}

Marine Hydrophysical Institute, Russian Academy of Sciences, Sevastopol, Russian Federation

*e-mail: vefim38@mail.ru

\begin{abstract}
On the basis of the reanalysis data with high spatial resolution and 36 years temporal coverage the spatial structure of wind speed and temperature fields in the Black Sea region for bora events in winter months was assessed. It is shown that bora development is followed by a formation of large-scale cyclonic circulation in the southeast part of the Black Sea. The airflow of the northwest edge of high Caucasus Mountains leads to the wind speed cyclonic vorticity over the sea; high Anatolian mountains block propagation of the air flows to the south and, thus, they jointly form a large-scale closed circulation cell. Regression dependences between the wind speed and temperature in Novorossiysk region are studied; they show that in winter strong northeast winds correspond to frontal-type bora activity which is accompanied by the air temperature decrease. The important feature of the temperature field during bora is revealed at that: temperature in the sea coastal area exceeds the one in the mainland foothill part of the region. For studying the physical mechanism of this phenomenon the atmospheric circulation computation (using WRF-ARW model) for specific Novorossiysk region bora event, which provided a detailed consideration of vertical structure components of wind speed and potential temperature in the coastal zone, above the sea, above the mountains and in the foothill mainland of the region, was carried out. It is shown that the mechanism of higher temperature formation in the sea coastal area is related to the air blocking above the windward slope of the mountain ridge and its replacement with warmer air from the upper layers of the atmosphere at the leeward slope.
\end{abstract}

Keywords: Novorossiysk region, bora, WRF-ARW model of atmospheric circulation, cyclonic vorticity.

DOI: $10.22449 / 1573-160 X-2017-4-26-34$

(C) 2017, V. V. Efimov, O. I. Komarovskaya

(C) 2017, Physical Oceanography

Introduction. Bora is traditionally defined as a strong, cold and gusty wind blowing from the coastal mountain ranges to the sea. In the Black Sea basin such winds often occur in the Crimean Mountains, as well as near Novorossiysk where, on average, 46 days with bora per year are observed. As a rule, a strong bora is accompanied by a significant temperature drop, sometimes down to $-25^{\circ} \mathrm{C}$. Along with the wind speeds reaching $30-35 \mathrm{~m} / \mathrm{s}$ and more, this causes numerous destructions [1].

A distinctiveness of bora-type wind is a significant spatial-temporal variability related to local inhomogeneity of orography and a coastline, as well as the features of the airflow of the mountains $[2,3]$. The main achievements in studying the disturbances introduced by orography into the thermodynamic processes of bora development are related to the application of numerical models. It should be pointed out review [4] where the results of studying of bora developing at the northeastern coast of the Adriatic Sea are given. In [5], where Novorossiysk bora in early February 2010 was numerically reproduced, it was shown that one of the causes of temporal variability during its development was a change of hydrodynamic regime of mountain airflow. This resulted in a change in a jet-stream structure itself (the bora). Some results of Novorossiysk bora numerical modeling are given in [6, 7].

At the same time Novorossiysk bora is not only a local phenomenon that covers Novorossiysk - Gelendzhik region. It is just a part of more general process - 
the invasion of cold air through the northeastern boundary of the sea which makes the strong impact on the entire eastern part of the Black Sea. Such invasions in this part of the sea can be considered as, for instance, one of the causes for cold intermediate layer (CIL) waters formation [8]. In winter cold air flux may lead to convective cooling of $30-40 \mathrm{~m}$ upper layer in the central eastern part of the sea. Its subsequent spreading can be one of CIL sources.

So far, the most complete review of synoptic conditions of Novorossiysk bora formation and aerological structure is given in [1]. On the basis of historical database analysis, bora classification according to four regimes with regard to hydrometeorological features of general atmospheric circulation (against the background of which bora is developed) is proposed in this work. There are four types of bora: drain, intra mass, monsoon and frontal-type. During the winter period the strongest type of bora is a frontal one related to the cold front passage at the southeastern periphery of Central European anticyclone. In wintertime, a catastrophic frontaltype bora with more than $30 \mathrm{~m} / \mathrm{s}$ wind speeds has $\sim 75 \%$ repeatability. Its duration is not more than 2-3 days and is accompanied by significant temperature decrease. Moreover, frontal-type bora is not localized in Novorossiysk region only; northeastern storm winds cover a large territory: the Crimea, the Sea of Azov, the south of Ukraine, the North Caucasus.

We note that the definition of bora [1] as a wind in Novorossiysk region with more than $15 \mathrm{~m} / \mathrm{s}$ speeds significantly expands the typification of this phenomenon and includes spring-summer-autumn cases of strong wind, which are not accompanied by significant temperature decrease and catastrophic consequences. Usually the cases of strong wind and significant temperature decreases in winter are considered to be a bora. In connection with this condition, further we will consider the features of winter bora development.

The data. The work is based on the data of atmospheric circulation regional reanalysis with high resolution applying $\operatorname{Reg} C M 4$ numerical model and on the input data of ERA-Interim reanalysis [9]. 18 vertical $\sigma$-levels are set in the model, the spatial resolution is $25 \times 25 \mathrm{~km}$, output data for the surface are predetermined with $1 \mathrm{~h}$ time-step, for $\sigma$-levels - with $6 \mathrm{~h}$ one. The calculations were carried out over 1979-2014 period. In this work for statistical estimates the output model data with 1 day time interval are used.

However, it should be pointed out that regional reanalysis still has insignificant resolution for adequate representation of bora features, as only large-scale orography peculiarities are taken into account. This results in a terrain smoothing and understating of mountain heights. Therefore, regional features related to the atmospheric circulation modeling in Novorossiysk region can be considered as qualitative assessments only. More detailed assessments can be obtained only when using atmospheric circulation numerical reanalysis with high spatial resolution. For statistical assessments numerical modeling on large time scales is required, and this is a task for the future. Therefore, in the present work bora modeling using highresolution regional numerical model of atmospheric circulation WRF-ARW [10] will be applied just for physical interpretation of several mesoscale features of this phenomenon. 
Wind field and temperature temporal structure at bora. Let us consider spatial structure (averaged over the winter months) of wind speed fields and temperature in the Black Sea region for the bora episodes. As a criterion for its development we choose the excess of the predetermined level by northeastern wind speed component value. Northeastern speed component $U_{\mathrm{n}}=-0,7(U+V)$, where $U$ and $V$ are meridional and zonal wind speed components at $10 \mathrm{~m}$ height in that point of reanalysis dataset, which is the closest to Novorossiysk, approximately corresponds to the speed which is normal to the Varada ridge near Novorossiysk. In Fig. 1, $a$ wind speed fields and temperatures at bora (i. e. averaged fields at $U_{\mathrm{n}}$ northeastern speed component which exceeds the chosen conditional bora criterion of $10 \mathrm{~m} / \mathrm{s}$ ) are shown, in Fig. 1, $b-$ at the opposite, southwestern wind.
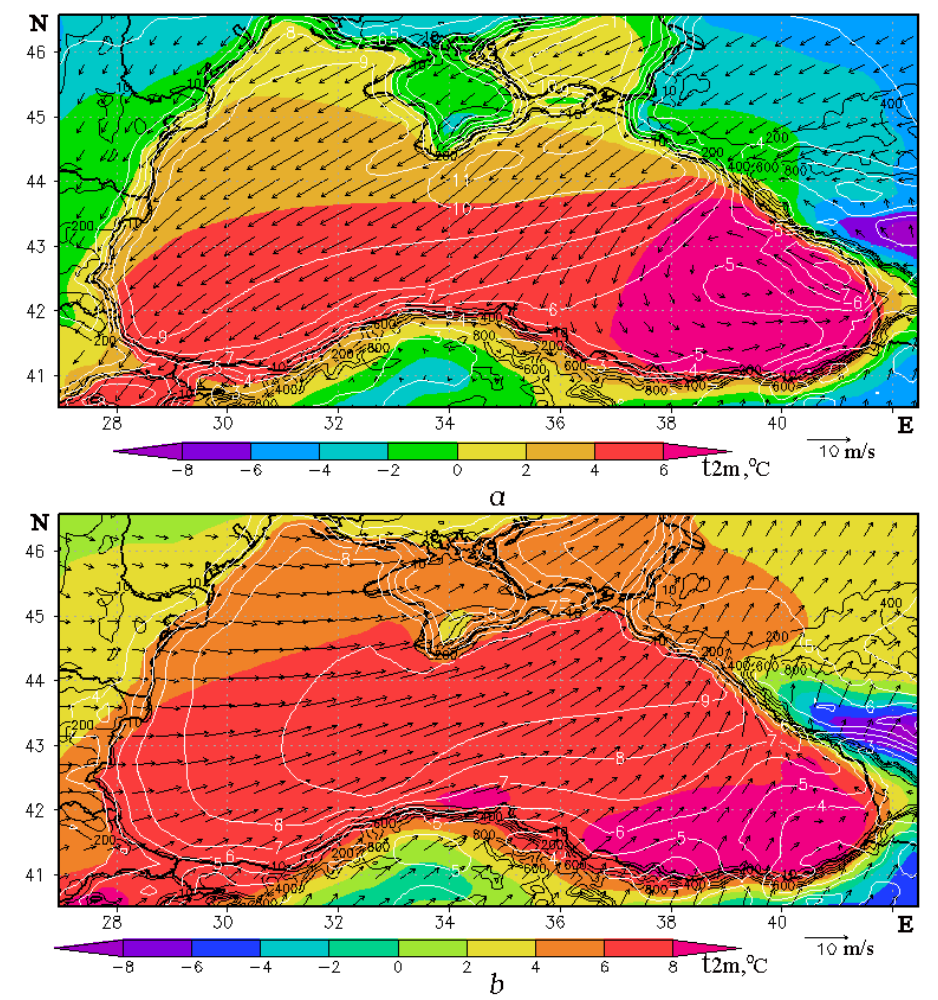

Fig. 1. Mean temperature fields at $2 \mathrm{~m}$ height (color), the fields of wind speed modules at $10 \mathrm{~m}$ height (isolines) and the ones of wind speed vectra at $10 \mathrm{~m}$ height (arrows) at bora ( $a$ ) and under the opposite southeastern wind $(b)$ in wintertime (January - March of 1979-2014) according to the data of the reanalysis carried out using $\operatorname{RegCM} 4$ numerical model

As can be seen, in the northeastern part of the sea averaged values of wind speed are more than $15 \mathrm{~m} / \mathrm{s}$ in comparison with $10 \mathrm{~m} / \mathrm{s}$ reference speed in Novorossiysk region. Cyclonic circulation, covering the entire southeastern part of the Black Sea, is a characteristic large-scale feature of wind speed field at bora. This feature is a consequence of two causes. The cyclonic vorticity is formed at a flow with a northeast baroclinic stream of the northeastern edge of high Caucasus Mountains [11]; moreover, rather high (up to 2-3 km) Pontic Mountains of Asia 
Minor serve as a barrier on the way of air propagation to the South in the atmospheric boundary layer. The features of near-surface air temperature field are large gradients in the coastal northeastern area (in the region of bora developing).

We note that the represented composites are the result of field averaging over the entire 36 years wintertime period. Besides, as it was mentioned above, the reanalysis does not provide a quantitative representation of all effects of air flow interaction with coastal mountains. So, it is interesting to consider direct temperature and wind speed fields for one of recent cases of strong bora. These fields were calculated using the numerical model with high spatial resolution.
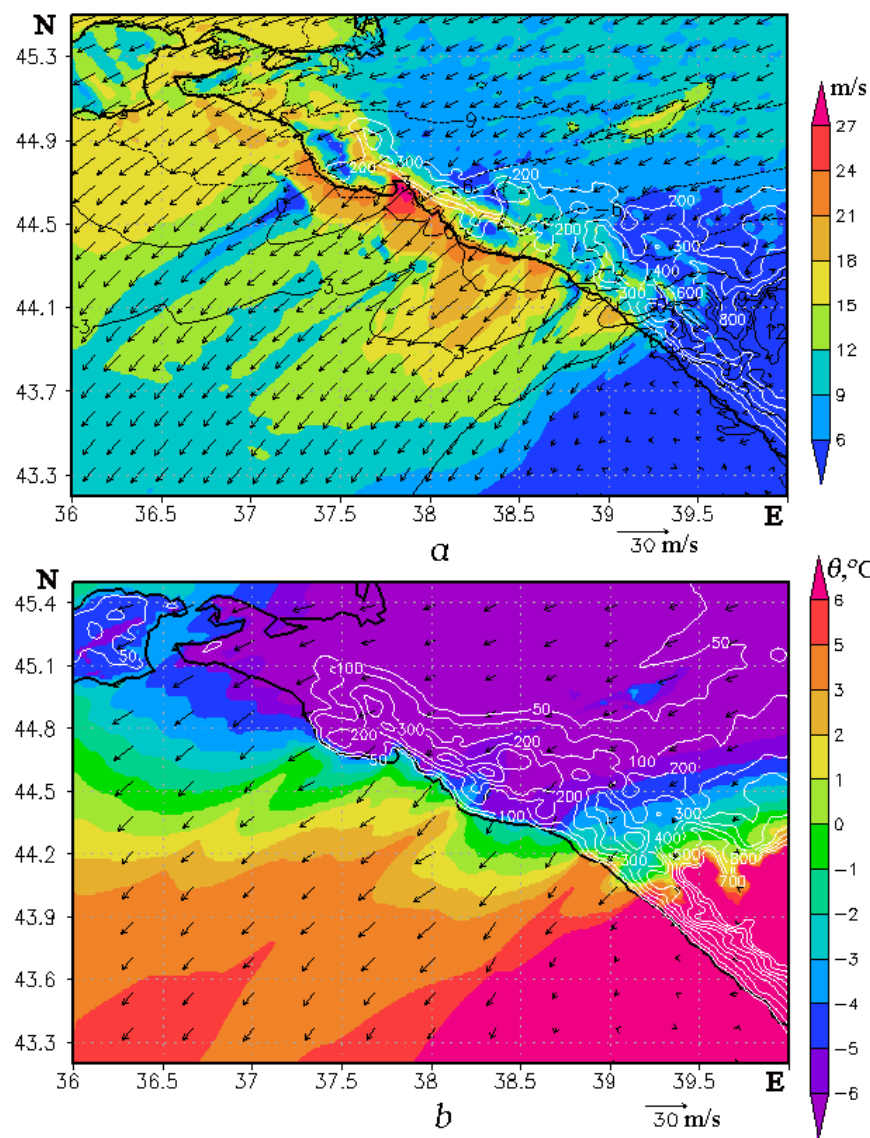

Fig. 2. Wind speed and temperature fields for the bora on 00 h, February 9, 2017: wind speed field at $10 \mathrm{~m}$ height (arrows) and wind speed modulus (color), potential temperature field at $2 \mathrm{~m}$ height (isolines) $-a$; potential temperature field at $2 \mathrm{~m}$ height (color) and wind field (arrows) $-b$

In Fig. 2 wind speed and temperature fields for the bora on February 9, 2017 are shown. Here the features of the fields stand out more clearly, in the "smeared out" form noted on the composites. Local area of the maximum wind with more than $27 \mathrm{~m} / \mathrm{s}$ speed is well-pronounced and falls directly on the Tsemes Bay. With the distance from the shore wind speed gradually decreases and long small-scale speed inhomogeneities, related to the features of orography and the coastline, can be seen. In the region of the coastal wind high speeds large surface temperature 
gradients stand out by the normal to the shore: in the narrow coastal area adjacent to the leeward slope of the mountains the temperature varies by $5-7^{\circ} \mathrm{C}$. As it will be shown below, this effect is directly related to the bora development features.

Temperature variation in the land-sea transition zone. Catastrophic cases of wintertime bora are accompanied by strong wind and temperature decrease. Therefore, sometimes it is assumed that a temperature decrease is a direct consequence of thermohydrodynamic processes at bora. For one of bora regimes - draintype one according to the terminology [1] - this is indeed the case. In fact, bora is a katabatic wind (a flow of near-surface cold wind flowing down from the top to the foot along the ridge slope), occurring as a result of night radiation cooling [12]. However, drain-type bora in wintertime refers to rare phenomena, in comparison with the frontal-type bora, and can not determine the properties of composite temperature fields. We are to consider averaged temperature variations according to the reanalysis data.

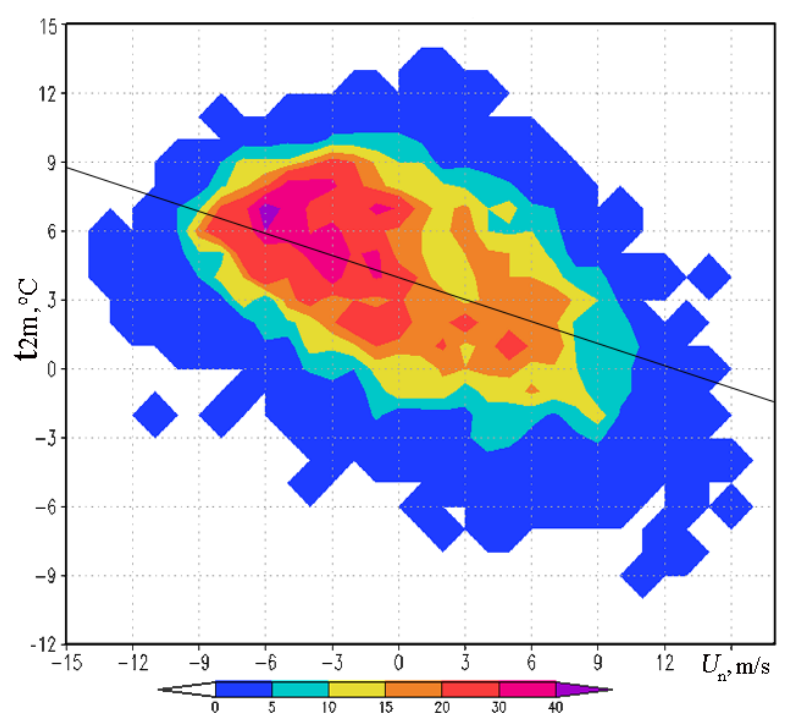

Fig. 3. Joint distribution for winter period (January - March 1979-2014) of southeastern wind speed component $U_{\mathrm{n}}\left(U_{\mathrm{n}}=\left\{-0,7 U_{10}, 0,7 V_{10}\right\}\right.$ where $U_{10}$ is zonal wind speed component at $10 \mathrm{~m}$ height, $V_{10}$ is a meridional one) and temperature in the closest to Novorossiysk sea point with $44.58^{\circ} \mathrm{N} ; 37.74{ }^{\circ} \mathrm{E}$ coordinates according to the data of the reanalysis carried out using RegCM4 numerical model

In Fig. 3 the regression graph of temperature dependence in the nearest to Novorossiysk sea point with $44.58^{\circ} \mathrm{N}, 37.74^{\circ} \mathrm{E}$ coordinates and $U_{\mathrm{n}}$ wind speed which is normal to the mountain ridge in the same point is shown. The scale demonstrates the number of points per $1 \times 1 \mathrm{~m} / \mathrm{s}$ element from 3248 total number (the number of winter days over 36 years given in the reanalysis data). It should be noted that the points in the first quarter of the graph correspond to the northeastern wind, i. e. to the wind direction at bora; in the second quarter - to the inshore wind. As it can be seen from the figure, an obvious negative relationship between the variations of temperature and wind speed value is observed. Correlation coefficient between them is -0.49 . Thus, the conclusion [1] about the predominance of 
frontal-type bora (related to cold northeastern air invasion causing the temperature decrease over all Novorossiysk coastal region under consideration) in the wintertime is confirmed.

Regression graph shown in Fig. 4, where $\Delta t$ values of temperature differences between the same sea point (which is close to Novorossiysk) and a land one with $45.02{ }^{\circ} \mathrm{N}, 37.96^{\circ} \mathrm{E}$ coordinates located just outside the mountainous area of the region depending on $U_{\mathrm{n}}$ wind speed component in the sea point are shown, is more interesting. There is a significant distribution asymmetry in regard to $\Delta t$ sign variation: in the first and the second quarters of the graph a predomination of points corresponding to higher temperatures above the sea (in comparison with the land) regardless of the wind direction is observed. Correlation coefficient between $U_{\mathrm{n}}$ speed and $\Delta t$ is equal to 0.37 .

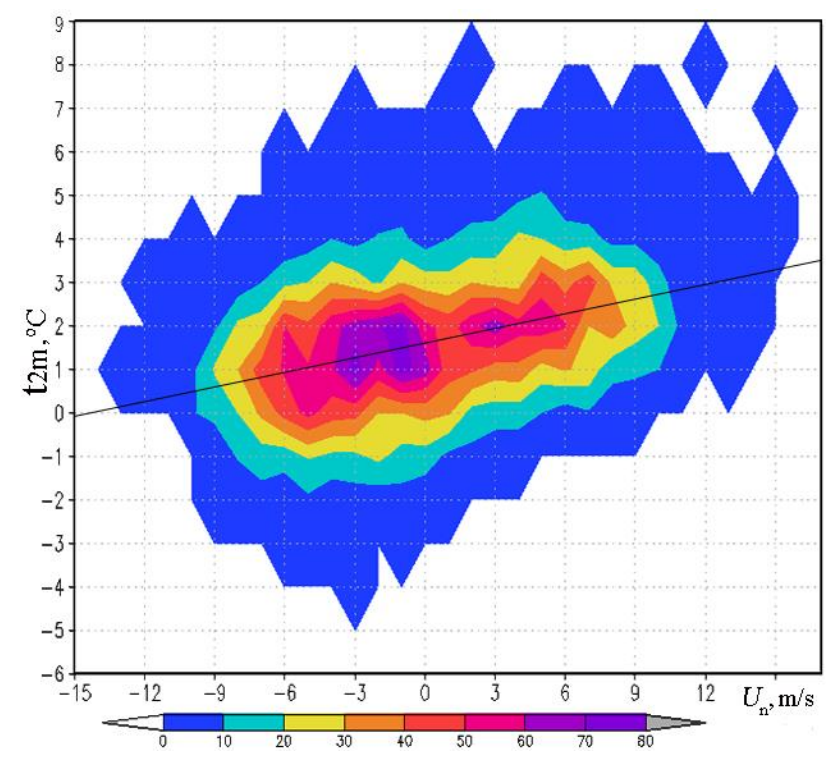

Fig. 4. Joint distribution for winter period (January - March 1979-2014) of southeastern wind speed component $U_{\mathrm{n}}\left(U_{\mathrm{n}}=\left\{-0,7 U_{10}, 0,7 V_{10}\right\}\right)$ in the point with $44.58^{\circ} \mathrm{N} ; 37.74{ }^{\circ} \mathrm{E}$ coordinates and differences of near-surface temperatures in this point and coastal one with $45.02{ }^{\circ} \mathrm{N} ; 37.96^{\circ} \mathrm{E}$ coordinates according to the data of reanalysis carried out using RegCM4 numerical model

The excess of temperatures above the sea in comparison with the temperatures above the land at southwestern wind raises no issues (in wintertime the advection of warmer near-water air to the land results in temperature raise above it, and thermal gradients decreases with wind speed increase) but positive relationship between $U_{\mathrm{n}}$ northeastern wind speed (i. e. at bora) and $\Delta t$ thermal gradients requires an explanation. Essentially, this means that at bora the temperature in the sea coastal region exceeds the one at the land in the foothill part of the region. At first glance, this contradicts the general idea that bora is accompanied by a temperature decrease over the leeward slope and the foot of the mountain range.

Physical mechanism of such phenomena is explained by Fig. 5, in which a vertical structure of $U_{\mathrm{n}}$ wind speed component and $\theta$ potential temperature (for brevity we define $\theta=\theta(\mathrm{K})-273.15)$ at the meridional normal to the ridge section which 
passes through the Tsemes Bay, i.e. through the local area of bora maximum speed shown in Fig. 2 is given. In general, both speed and temperature have the features characteristic of mountain winds (frontal-type bora [13-15] belongs to them). The area of breaking of internal gravity waves above the leeward mountain slope is represented well by vertical sections of $\theta$ isolines. The indicator of blocking of air stream flowing into the mountain is the crossing of the windward slope by $\theta$ isolines. Bora jet flow (pressed to the surface) with up to $30 \mathrm{~m} / \mathrm{s}$ speeds can be also clearly seen in Fig. 5. The result of well-mixed turbulent area formation, associated with the breaking of internal waves, is the bora flow pressed to the surface. Its source is a warm (in terms of potential temperature) air from the upper atmosphere layers above the windward slope. As is obvious, the differences of surface air temperatures in the foothill part of the ridge and in the coastal zone makes up $\sim 2-3{ }^{\circ} \mathrm{C}$.

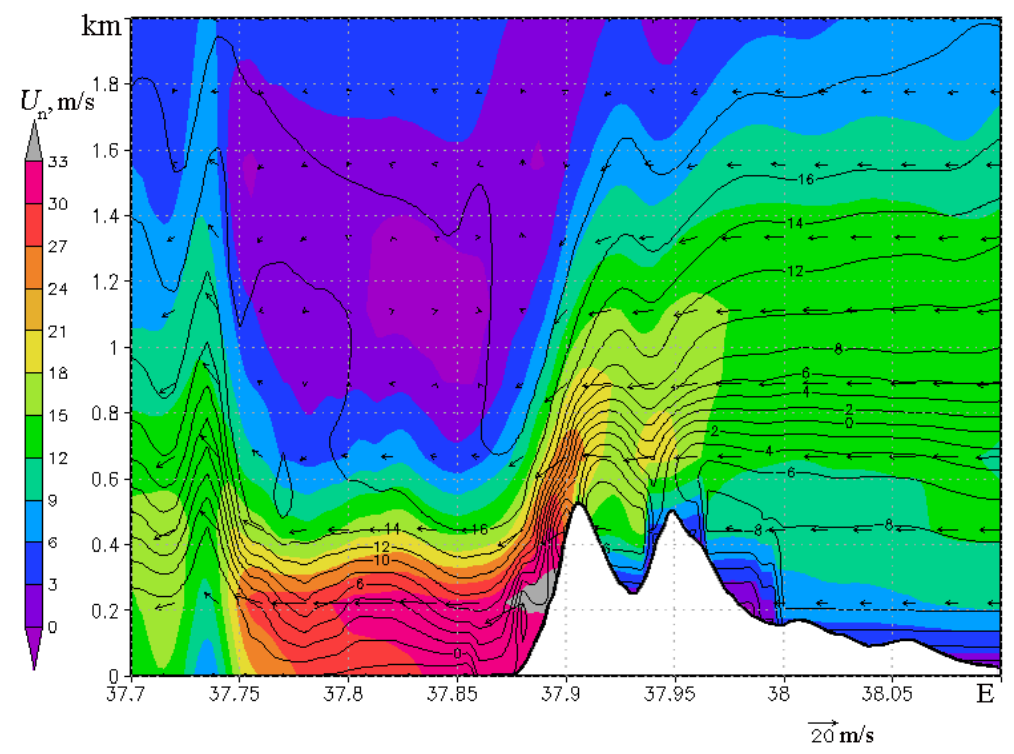

Fig. 5. Vertical structure of $U_{\mathrm{n}}$ southeastern wind speed component (color), $\theta$ potential temperature (isolines) and speed vectra (arrows) in the vertical plane in $\{u, 5 \times w\}$ coordinates (where $u$ is zonal wind speed component, $w$ is a vertical one) for the section $\left(44.5-44.9^{\circ} \mathrm{N} ; 37.7-38.1{ }^{\circ} \mathrm{E}\right.$ at $00 \mathrm{~h}$ 09.02.2017), which is perpendicular to the ridge, according to numerical simulation data using the $W R F-A R W$ model.

Thus, more warm air above the leeward slope of the ridge is a result of blocking of surface air from the foothill land part and of its replacement with warmer air from the upper atmosphere layers. At the regression graph (Fig. 4) this thermal gradient is represented by the points in the first quarter. As the frontal bora is related to the passage of cold air front (in wintertime its temperature can decrease down to $-10 \ldots-15{ }^{\circ} \mathrm{C}$ ), its abovementioned thermohydrodynamical effect leads to the temperature raise in the sea coastal zone without changing of general temperature decrease character during the cold front passage [1]. If we imagine an experiment with the disappearance of Varada ridge, then the invasion of cold air through the northeastern boundary of the Black Sea would cause more moderate wind speeds but also lower air temperatures. This blocking effect in the area of low Varada 
ridge is relatively small. However, with the move along the coast to the South and the Caucasus Mountains height rising, the blocking of northeastern flow by the mountains should increase and the mentioned thermal gradient will increase too. In Fig. 2 this feature is reflected in a rapid increase of coastal air temperature in Tuapse area.

Conclusion. The data of climatic reanalysis with the high spatial resolution $(25 \times 25 \mathrm{~km})$ allowed us to construct the composites of wind speed and temperature fields for the winter period corresponding to Novorossiysk bora events. As it was revealed, bora development is accompanied with the formation of large-scale cyclonic circulation in the southeastern part of the Black Sea. As a result of the air flowing over the northwestern edge of the high Caucasus Mountains, wind speed cyclonic vorticity occurs above the sea as well as the high Anatolian Mountains restrict the propagation of air flows to the South and together with the Caucasus Mountains form the enclosed large-scale circulation cell.

Regression dependences between the wind speed and temperature in Novorossiysk region, constructed according to 36-years reanalysis data demonstrate that in winter strong winds of northeastern direction correspond to frontal-type bora events at which its development is accompanied with air temperature decrease. An important feature of the temperature field is revealed at that: the increased values of surface air temperature in the coastal part in comparison with the one in the foothill areas of the land. Bora development numerical simulation with high spatial resolution explains the mechanism of this phenomenon which is related to the air blocking above the windward slope of the mountain ridge and its replacement by warmer overlying air on the leeward slope.

Acknowledgements. The calculations were carried out at computational cluster of Marine Hydrophysical Institute of RAS.

The research was carried out within the framework of State Order No. 0827 2015 - 0001 "Fundamental research of the processes in the ocean - atmosphere lithosphere system determining spatial-temporal variability of the global and regional scale environment and climate".

\section{REFERENCES}

1. Gusev, A.M. ed., 1959. Novorossijskaya Bora [The Novorossiysk Bora]. In: MHI AN SSSR, 1959. Trudy Morskogo Gidrofizicheskogo Instituta AN SSSR. Vol. 14, 140 p. (in Russian).

2. Efimov, V.V. and Barabanov, V.S., 2013. Simulation of Bora in Novorossiysk. Russian Meteorology and Hydrology, [e-journal] 38(3), pp. 171-176. doi:10.3103/S1068373913030059

3. Smith, R.B., 1989. Hydrostatic Airflow over Mountains. Adv. Geophys., [e-journal] 31, pp. 1-41. doi:10.1016/S0065-2687(08)60052-7

4. Grisogono, B. and Beluŝić, D., 2009. A Review of Recent Advances in Understanding the Meso- and Microscale Properties of the Severe Bora Wind. Tellus, [e-journal] 61(1), pp. 1-16. Available at: http://www.tandfonline.com/doi/pdf/10.1111/j.1600-0870.2007.00369.x [Accessed 7 June 2016].

5. Efimov, V.V. and Barabanov, V.S., 2013. Gustiness of the Novorossiysk Bora. Russian Meteorology and Hydrology, [e-journal] 38(12), pp. 840-845. doi:10.3103/S1068373913120054 
6. Efimov, V.V. and Barabanov, V.S., 2013. Black Sea Bora Modeling. Izvestiya, Atmospheric and Oceanic Physics, [e-journal] 49(6), pp. 632-641. doi:10.1134/S0001433813060066

7. Gavrikov, A.V. and Ivanov, A.Y., 2015. Anomalously Strong Bora over the Black Sea: Observations from Space and Numerical Modeling. Izvestiya, Atmospheric and Oceanic Physics, [e-journal] 51(5), pp. 546-556. doi:10.1134/S0001433815050059

8. Ovchinnikov, M.M. and Popov, Yu.I., 1990. Osobennosti Formirovaniya Kholodnogo Promezhutochnogo Sloya v Chernom More pri Ekstremal'nykh Zimnikh Usloviyakh [The Features of Cold Intermediate Layer Formation in the Black Sea under Extreme Winter Conditions]. In: SOI, 1990. Trudy GOIN [State Oceanographic Institute Proceedings]. Vol. 190, pp. 132-151 (in Russian).

9. Anisimov, A.E., Yarovaya, D.A. and Barabanov, V.S., 2015. Reanalysis of Atmospheric Circulation for the Black Sea-Caspian Region. Physical Oceanography, [e-journal] (4), pp. 1325. doi:10.22449/1573-160X-2015-4-13-25

10. Skamarock, W.C., Klemp, J.B., Dudhia, J., Gill, D.O., Barker, D.M., Wang, W. and Powers, J.G., 2008. A Description of the Advanced Research WRF Version 3. NCAR Technical Note. $N C A R / T N-475+S T R$, [e-book] Boulder, Colorado, USA: Mesoscale and Microscale Meteorology Division National Center for Atmospheric Research, 113 p. doi:10.5065/D68S4MVH

11. Epifano, C.C. and Rotunno, R., 2005. The Dynamic of Orographic Wake Formation in Flows with Upstream Blocking. J. Atmos. Sci., [e-journal] 62(9), pp. 3127-3150. doi:10.1175/JAS3523.1

12. Grisogono, B., 2003. Post-Onset Behaviour of the Pure Katabatic Flow. Boundary-Layer Meteorology, [e-journal] 107(1), pp. 157-175. doi:10.1023/A:1021511105871

13. Gill, A.E., 1986. Atmosphere-Ocean Dynamics. Cambridge: Academic Press, 662 p.

14. Lin, Y.-L., 2007. Mesoscale Dynamics. Cambridge: Cambridge University Press, 630 p. Available at: http://www.prometeus.nsc.ru/eng/exhibit/09/09-10-13/cont29f.ssi [Accessed 10 July 2016].

15. Smith, R.B., 1985. On Severe Downslope Winds. J. Atmos. Sci., [e-journal] 42(23), pp. $2597-$ 2603. doi:10.1175/1520-0469(1985)042<2597:OSDW>2.0.CO;2 